\title{
Chaperone Use by Family Physicians During the Collection of a Pap Smear
}

Pamela Rockwell, DO'

Terrence E. Steyer, $M D^{2}$

Mack T. Ruffin IV, MD, MPH

'Department of Family Medicine, University of Michigan, Ann Arbor, Mich

${ }^{2}$ Department of Family Medicine, Medical University of South Carolina, Charleston, SC

\begin{abstract}
BACKGROUND We wanted to determine whether variations exist in use of a chaperone during the performance of a pelvic examination by family physicians.
\end{abstract}

METHODS A self-administered questionnaire was mailed to 5,000 randomly selected active members of the American Academy of Family Physicians.

RESULTS There were 3,551 survey responses (71\% response rate) and 2,748 useable questionnaires. Most respondents (75.4\%) reported routinely using a chaperone in the room during the collection of a Papanicolaou (Pap) smear. Significantly $(P<.00001)$ more male physicians $(84.1 \%)$ than female physicians $(31.4 \%)$ reported using a chaperone. Physicians reporting routine use of a chaperone were significantly younger $(P=.01)$ and did fewer Pap smears per month $(P<.00001)$. Regional reporting of chaperone use varied significantly $(P<$ .00001 ), with $71.6 \%$ reporting use in the Northeast, $89.0 \%$ in the South, $65.7 \%$ in the Midwest, and $72.4 \%$ in the West.

CONCLUSION Family physicians vary considerably in the reported use of a chaperone during the collection of a Pap smear. The variation could reflect different regional or local norms, efficiency or resource issues in high-volume clinical settings, or other interpersonal factors. These issues need to be explored in more depth.

Ann Fam Med 2003;1:218-220. DOI: 10.1370/afm.69.

\section{INTRODUCTION}

Historically, chaperone use during pelvic examinations was first encouraged for the comfort of the patient, and gradually chaperones were advocated for the purpose of legal protection. ${ }^{1}$ Additional rationales for use of chaperones are convenience and time efficiency, although there are no supporting data. Little consistency and uniformity, however, are found in the use of chaperones during a pelvic examination. ${ }^{2-7}$

Relatively few studies have explored the issue of chaperone use based on physician variables. Published data suggest that physician specialty and physician sex might contribute to the variation in chaperone use, but these data are limited to small samples, one geographic location, or one medical society. No existing study has a sample population that is representative of practicing family physicians.

We proposed to test the hypothesis that family physicians' use of a chaperone during a routine pelvic examination to collect a Papanicolaou (Pap) smear would vary by physician sex but not by age, other physician characteristics, number of Pap tests done, or geographic location of the practice.

To address this hypothesis, we used data previously collected with the primary intent to gather information on Pap smear collection and processing techniques. One aspect of the study queried physicians about their routine use of chaperones during the collection of a Pap smear.
Mack T. Ruffin IV, MD, MPH

Department of Family Medicine University of Michigan Health System Ann Arbor, MI 48109-0708 mruffin@umich.edu 


\section{METHODS}

\section{Data Collection Instrument}

A self-administered questionnaire was developed to gather information on Pap smear collection and processing techniques. The reliability was determined for each item of the questionnaire using kappa statistics for categorical data and correlation coefficients for continuous data. The reliability was excellent, with a kappa statistic range of .75 to .90 and a correlation coefficient range of .83 to .90 . The questionnaire was sequenced to follow the steps in collecting a Pap smear to facilitate completion. ${ }^{8}$ The issue of using chaperones during a Pap smear was a secondary item.

The self-administered questionnaire was mailed with a cover letter that included an introduction of the project, quotes from nationally recognized leaders in family

\section{Table 1. Characteristics of Family Physicians Reporting the Use of Chaperones During the Collection of a Pap Smear and Logistic Regression Model}

\begin{tabular}{|c|c|c|c|}
\hline \multirow[b]{2}{*}{ Variable } & \multirow[b]{2}{*}{$\begin{array}{l}\text { Percent } \\
\text { Reporting Use } \\
\text { of Chaperone }\end{array}$} & \multicolumn{2}{|c|}{ Logistic Regression } \\
\hline & & $\begin{array}{l}\text { Unadjusted } \\
\text { Odds Ratio } \\
(95 \% \mathrm{Cl})\end{array}$ & $\begin{array}{l}\text { Adjusted } \\
\text { Odds Ratio } \\
(95 \% \mathrm{Cl})\end{array}$ \\
\hline \multicolumn{4}{|l|}{ Sex } \\
\hline Female* & 31.4 & 1 & 1 \\
\hline Male & 84.1 & $11.6(9.2-14.7)$ & $15.4(11.7-20.1)$ \\
\hline \multicolumn{4}{|c|}{ Age of physician ${ }^{\dagger}$} \\
\hline$\leq 35$ years & 55.6 & 1 & 1 \\
\hline $36-50$ years & 74.0 & $0.89(0.70-1.12)$ & $0.60(0.43-0.84)$ \\
\hline$\geq 51$ years & 78.2 & $1.16(0.89-1.51)$ & $0.60(0.34-1.04)$ \\
\hline \multicolumn{4}{|c|}{ Region of practice* } \\
\hline South & 89.0 & $4.2(3.2-5.5)$ & $6.1(4.5-8.3)$ \\
\hline Northeast & 71.6 & $1.3(1.0-1.7)$ & $1.5(1.1-2.0)$ \\
\hline Midwest & 65.7 & 1 & 1 \\
\hline West & 72.4 & $1.4(1.1-1.7)$ & $1.6(1.1-2.1)$ \\
\hline \multicolumn{4}{|c|}{$\begin{array}{l}\text { Number of Pap smears } \\
\text { performed per month* }\end{array}$} \\
\hline$<20$ & 81.4 & 1 & 1 \\
\hline$\geq 20$ & 69.5 & $0.52(0.43-0.62)$ & $0.76(0.59-0.96)$ \\
\hline \multicolumn{4}{|c|}{ Board certification ${ }^{\dagger}$} \\
\hline Certified & 74.9 & 1 & 1 \\
\hline Pending & 79.2 & $1.24(0.93-1.64)$ & $1.29(0.87-1.91)$ \\
\hline Not certified & 78.7 & $1.27(0.63-2.57)$ & $2.02(0.68-6.06)$ \\
\hline \multicolumn{4}{|l|}{ Years in practice } \\
\hline$\leq 15$ years & 74.3 & 1 & 1 \\
\hline$>15$ years & 78.1 & $1.23(1.02-1.50)$ & $0.67(0.43-1.04)$ \\
\hline \multicolumn{4}{|c|}{ Location of practice* } \\
\hline Rural & 77.5 & $1.23(1.03-1.47)$ & $1.05(0.82-1.33)$ \\
\hline Urban & 73.7 & 1 & 1 \\
\hline \multicolumn{4}{|c|}{$\begin{array}{l}\text { Note: As of January } 2003 \text {, the American Academy of Family Physicians had } 52,506 \text { active members: } 72 \% \\
\text { were men, } 61 \% \text { were white, } 87 \% \text { were board certified, and the regional distribution was Northeast } 14.1 \% \text {, } \\
\text { Midwest } 28.2 \% \text {, West } 20.4 \% \text {, and South } 32.5 \% \text {. The mean age was } 44.6 \text { years. } \\
\text { Pap }=\text { Papanicolaou; } C 1=\text { confidence interval. } \\
* P<.001 \text {. } \\
+P \leq .01 \text {. }\end{array}$} \\
\hline
\end{tabular}

practice supporting the study, and an envelope with return postage. Six waves of mailed contacts at 2 -week intervals ( 2 surveys and 2 reminder cards) were followed by a telephone call to any remaining nonrespondents.

The study sample was 5,000 randomly selected active members of the American Academy of Family Physicians (AAFP). The total population at the time of sampling was 38,095 active members, 33,141 men and 4,950 women.

\section{Data Analysis}

Data analysis was performed using STATA Release 6.0 statistical analysis software. Initially, frequencies and summary statistics were calculated on all variables. Next, bivariate analysis was performed using chi-square and $t$ tests, as appropriate, with the outcome of use of a chaperone (yes/no). Variables with significant association in the bivariate analysis with chaperone use $(P \leq .05)$ were used in logistic regression analysis. Logistic regression models were developed using both forward and backward stepwise regression. Both unadjusted and adjusted logistic regression models were created to determine odds ratios for the independent variables. A Hosmer-Lemeshow goodness-of-fit test was performed to ensure the appropriateness of the model.

\section{RESULTS}

The responses to the mailed physicians' survey were 3,551 (71\% response rate) with 2,748 (55\%) useable questionnaires. The reasons for excluding the 803 responses were that cervical cancer screening was not part of the physician's clinical practice, 466 (58\%); the physician was no longer involved in patient care, 249 $(31 \%) ;$ or the physician was no longer alive, $88(11 \%)$. Differences were not found between respondents $(3,551)$ and nonrespondents $(1,449)$ by age (mean age 44.8 years compared with 49.1 years $)$ and sex ( $82.7 \%$ male compared with $85.2 \%$ female). Table 1 highlights the demographics of the participants in this survey.

Of the 1,449 nonresponders, 800 were reached by telephone. Among these 800 physicians, 384 (48\%) did not see women, 240 (30\%) did not 
screen for cervical cancer in their practice, $96(12 \%)$ had moved to another practice location, and $80(10 \%)$ were no longer in clinical practice. No other information was available on the nonresponders for comparison.

Table 1 shows the results of the unadjusted and adjusted logistic regression models for predicting use of a chaperone during the collection of a Pap smear. The most predictive variable for the use of a chaperone was physician sex, with men being significantly more likely (odds ratio $[\mathrm{OR}]=15.4 ; 95 \%$ confidence interval $[\mathrm{CI}]$, 11.2-20.1) than women to use chaperones. The number of Pap smears performed per month was also important, in that those family physicians who performed 20 or more Pap smears per month were significantly less likely to use chaperones $(\mathrm{OR}=0.76 ; 95 \%$ $\mathrm{CI}, 0.59-0.96)$. Finally, the geographic location of a practice was significantly associated with the use of a chaperone. Physicians in the South were significantly more likely to use chaperones than those in the Midwest $(\mathrm{OR}=6.1 ; 95 \% \mathrm{CI}, 4.5-8.3)$.

\section{DISCUSSION}

Among a random sample of active members of the AAFP, the hypothesis that male physicians would report use of a chaperone more often than female physicians was confirmed. Other physician characteristics were found to be associated with reported chaperone use, refuting our other hypothesis. Those family physicians who performed fewer than 20 Pap smears per month were significantly more likely to use chaperones than those who performed more than 20. Physicians in the South used chaperones more often than physicians did in the Northeast, the Midwest, and the West. It is interesting that Southern female physicians were as likely to report chaperone use as Midwestern male physicians.

Some limitations to this study can be noted. First, physician behavior was self-reported, which might not be valid. The primary focus of the survey, however, was on Pap smear collection and processing, not the use of chaperones, so the responses might be less biased than had the primary intent of the survey been to target the issue of chaperone use. Second, the study population was 5,000 randomly selected active members of the AAFP. This group might not reflect the practices of all family physicians; AAFP members might be more informed because of required continuing medical education. Third, although the response rate to the survey was $71 \%$, which is quite good, variation in chaperone use might still be significantly different among the nonresponders.

The use of chaperones during gynecologic examinations remains a controversial issue with no formal guide- lines or legal mandates. The topic is poorly addressed by the medical literature and by our current medical education system. No consensus is found among state medical and osteopathic boards on the use of a chaperone. ${ }^{9}$ From the legal perspective, the recommendations are nearly unanimous in strongly supporting the use of chaperones. Many questions related to this issue are unanswered. Does chaperone use decrease malpractice claims? Does chaperone use have an impact on clinical efficiency, as the inverse relationship with the volume of Pap smears performed suggests? What are the regional influences contributing to the geographic variation in reported use of a chaperone? We believe the question with highest priority is, What is the perspective of patients?

To read commentaries or to post a response to this article, see the online version at http://www.annfammed.org/cgi/content/full/1/4/218.

Key words: Cervical intraepithelial neoplasia; professional practice; vaginal smears

Submitted September 26, 2002; submitted, revised, June 17, 2003; accepted June 19, 2003.

Funding support: The original study was supported by grants from the Research Council of the Department of Family Practice and Community Health at the University of Minnesota, the Bureau of Health Professions HRSA Grant for Faculty Development in Family Medicine, the Minnesota Medical Foundation, the American Academy of Family Physicians Foundation, the American Cancer Society, and the Research Committee of the Department of Family Practice at the University of Michigan. We would also like to acknowledge the Robert Wood Johnson Foundation Clinical Scholars program for the support of Dr. Steyer and the support of the National Cancer Institute (K24 CA 80846) for Dr. Ruffin.

Acknowledgments: We would like to thank Sonya DeMonner for statistical assistance and Kathy Carter for editorial assistance.

\section{References}

1. Clyman SG. Why do we chaperone the female pelvic exam? Del Med J. 1982;54:105-108.

2. Gilchrist V, Gillanders WR, Gemmel DJ. Chaperoning practices of Ohio family physicians. Fam Med. 1992;24:386-389.

3. Johnson NR, Philipson EH, Curry SL. Chaperone use by obstetrician/ gynecologists. J Reprod Med. 1999;44:423-427.

4. Jones RH. The use of chaperones by general practitioners. J R Coll Gen Pract. 1983;33:25-27.

5. Renfroe WO, Replogle WH. Chaperone use in primary care. Fam Med. 1991;23:231-233.

6. Sanders JM Jr, DuRant RH, Chastain DO. Pediatricians' use of chaperones when performing gynecologic examinations on adolescent females. J Adolesc Health Care. 1989;10:110-114.

7. Speelman A, Savage J, Verburgh M. Use of chaperones by general practitioners. BMJ. 1993;307:986-987.

8. Dillman DA. Mail and Telephone Surveys: The Total Design Method. New York, NY: Wiley; 1978.

9. Stagno SJ, Forster H, Belinson J. Medical and osteopathic boards' positions on chaperones during gynecologic examinations. Obstet Gynecol. 1999;94:352-354. 